\title{
Preprocedural Anxiety and Pain Perception Following Root Surface Debridement in Chronic Periodontitis Patients
}

\author{
Vanaja Krishna Naik ${ }^{1,3}$, Aruna Balasundaram¹, Devapriya Appukuttan¹, Deepavalli Arumuga Nainar², Michael Robert Milward³, Dhayanand John Victor ${ }^{1}$, \\ Mohammed Junaid ${ }^{4}$ \\ ${ }^{1}$ Department of Periodontics, SRM Dental College, ${ }^{2}$ Department of Periodontics, Ragas Dental College and Hospital, Chennai, Tamil Nadu, India, ${ }^{3}$ The School of \\ Dentistry, College of Medical and Dental Sciences,University of Birmingham, United Kingdom, ${ }^{4}$ Department of Public Health Dentistry, Meenakshi Ammal Dental \\ College and Hospital, Chennai, Tamil Nadu, India
}

\section{Abstract}

Background: The aim of this study was to evaluate and compare preprocedural dental anxiety levels and postprocedural pain perception in chronic periodontitis patients during conventional-staged root surface debridement (RSD) and single-stage RSD. Materials and Methods: Thirty-seven adult generalized chronic periodontitis patients requiring RSD were recruited in this study. Preprocedural anxiety levels were assessed using a self-reported questionnaire and postprocedural pain perceptions were assessed using $0-10 \mathrm{~cm}$ visual analog scale. The subject population was divided into two groups: staged RSD $(n=18)$ and single-stage RSD $(n=19)$. Staged RSD patients visited four times as opposed to single-stage RSD patients. Data were subjected to Pearson Chi-square test, Mann-Whitney U-test, and Spearman's rank correlation. Results: There was no statistically significant difference in dental anxiety levels or pain perceptions in both the groups. Within Group 1, there was statistical significant difference in dental anxiety levels between visit 4 and visit $3(P=0.037)$ and pain perception between visit 3 and visit $1(P=0.005)$, visit 4 and visit $1(P=0.002)$, and visit 4 and visit $2(0.04)$ was statistically significant. There was a positive correlation of anxiety questionnaire $(\mathrm{Q} 1-\mathrm{Q} 4)$ to the pain score in Group 1 which was statistically significant and in single-stage RSD. Conclusion: Conventional quadrant-wise RSD tends to cognitively condition the anxiety experience thus influencing pain experience.

Keywords: Chronic periodontitis, dental anxiety, pain, patient-centered outcomes, root surface debridement, visual analog scale

\section{INTRODUCTION}

Dental anxiety and fear are strong negative feelings associated with dental treatment. Dental anxiety was described by Klingberg and Broberg as a state of apprehension that something dreadful is going to happen in relation to dental treatment or certain aspects of dental treatment. ${ }^{[1]}$ Dental anxiety is a multidimensional construct that consists of somatic, cognitive, and emotional elements and describes a general state that is not stimulus specific. This trait in an individual may result in avoidance of dental treatment. ${ }^{[2]}$ The experience of pain during dental procedures is a concern to many individuals. Hence, all members of the dental team including periodontists or dental hygienists must aim to minimize the degree of discomfort during periodontal procedures such as scaling and root surface debridement (RSD) ${ }^{[3]}$

There are reports in periodontal literature related to patients' perception of pain and discomfort during periodontal probing, ${ }^{[4]}$ scaling, ${ }^{[5]} \mathrm{RSD},{ }^{[3]}$ periodontal surgery, ${ }^{[6]}$ and maintenance

\begin{tabular}{|l|l|}
\hline \multicolumn{2}{|c|}{ Access this article online } \\
\hline Quick Response Code: & Website: \\
\hline & www.jnsbm.org \\
\hline & \\
\hline
\end{tabular}

treatments. ${ }^{[7]}$ However, the impact on patients in regard to single-visit or multi-visit RSD has yet to be fully investigated.

The treatment of chronic periodontitis primarily involves the reduction or elimination of bacteria present in the plaque biofilm. ${ }^{[8]}$ The periodontal pathogens can establish not only in periodontal pockets but also on the tongue, tonsils, or on the other oral mucous membranes. These sites may represent a potential reservoir for the reinfection of adjacent sites following active periodontal treatment. ${ }^{[9,10]}$

To avoid the risk of intraoral bacterial translocation to recently instrumented and healing periodontal sites, Leuven group

Address for correspondence: Dr. Vanaja Krishna Naik, Bhandal Dental Practice, Dental Surgery, 148 High Street, Cradley Heath, West Midlands, B64 5HJ, United Kingdom. E-mail: dr_vanajanaik@yahoo.com

This is an open access article distributed under the terms of the Creative Commons Attribution-NonCommercial-ShareAlike 3.0 License, which allows others to remix, tweak, and build upon the work non-commercially, as long as the author is credited and the new creations are licensed under the identical terms.

For reprints contact: reprints@medknow.com

How to cite this article: Naik VK, Balasundaram A, Appukuttan D, Nainar DA, Milward MR, Victor DJ, et al. Preprocedural anxiety and pain perception following root surface debridement in chronic periodontitis patients. J Nat Sc Biol Med 2018;9:82-9. 
introduced the concept "one visit full mouth disinfection." This concept utilizes instrumentation of periodontal pockets and use of antiseptic disinfection for the remaining sites in the oral cavity within $24 \mathrm{~h}^{[11]}$

The studies on the clinical efficacy of the full mouth disinfection versus conventional multi-visit approach suggest only minor differences between the two protocols. ${ }^{[12-14]}$ Nevertheless, these conclusions reflect the therapeutic outcomes clinically based rather than patient-centered outcomes which must also be considered while selecting a treatment. ${ }^{[15]}$ Nonsurgical periodontal therapies are often perceived as stressful and painful by the patient. ${ }^{[3]}$ However, to our knowledge, there are very few studies in the literature comparing patient perceptions of single-visit RSD versus conventional multi-visit debridement in terms of anxiety and pain. Hence, this study aimed to assess the difference in preprocedural anxiety and postoperative pain levels in multi-visit and single-visit RSD approaches.

The objectives of this study were:

- To assess and compare the preprocedural anxiety levels in chronic periodontitis patients who were undergoing conventional multi-visit and single-visit RSD

- To assess and compare the postoperative pain perception in chronic periodontitis patients who underwent conventional multi-visit and single-visit RSD

- To correlate the anxiety levels to pain perception in patients undergoing multi-visit and single-visit RSD.

\section{Materials and Methods}

\section{Patient sample}

Seventeen male and twenty female patients with generalized chronic periodontitis (GCP) were included in this study. All subjects were recruited from the Department of Periodontics, SRM Dental College, Ramapuram, Chennai, India (Ethical Committee Approval number SRMU/MandHS/SRMDC/2010/ M.D.S-Staff/103). Patients with GCP with the clinical evidence of probing depths $\geq 4 \mathrm{~mm}$, presence of more than 24 teeth with a minimum of four molars, no previous history of periodontal therapy, and with good systemic health (as assessed by the recruiting periodontist) were included in this study. ${ }^{[16]}$ The assessment criteria for generalized chronic periodontitis was according to American Academy of Periodontology 1999 classification. ${ }^{[16]}$

Patient who were on antibiotics and analgesics in the last 6 weeks, patients with the history of systemic diseases which interfere with the pain perception, such as neurological or psychiatric disorders and who were on medications which interfere with pain perception were also excluded from the study. In addition, patients presenting with acute dental, periapical/periodontal pain, dentinal hypersensitivity, and subjects with orthodontic and prosthetic appliances were excluded from the study. Finally, patients who did not attend all appointments were excluded from the study.
The literature suggests that age, sex, and socioeconomic status (SES) of an individual can influence fear and anxiety. Tuba TaloYildirim 2016 in their study suggested statistically significant difference between the levels of dental anxiety and sociodemographic status; hence, we selected individuals belonging to similar SES so as to eliminate any bias incorporation. ${ }^{[17]}$ The Kuppuswamy scale is recognized as a tool to measure SES in the urban population. This validated scale utilizes an online tool which was used in this study and utilized SES based on 2013 criteria. ${ }^{[18]}$

\section{Study design}

This is a randomized, prospective, single-blind, controlled clinical study. This study was conducted from January 2013 to December 2013. This study was approved by the Research Ethics Committee of the SRM Dental College, Ramapuram, Chennai, India. Patients were recruited based on the selection criteria and were randomly assigned to one of the following groups [Figure 1].

Group 1: Conventional multi-visit RSD, Group 2: Single-visit RSD.

The sample size was calculated based on the primary outcome measure, i.e., effect of RSD on preprocedural anxiety levels and pain perception obtained from the results of pilot study. Thus, a minimum sample size was determined to be 16 in each group $(\alpha=0.05$ power $90 \%)$. The proposed sample size of 16 was adjusted to 18 based on hospital records of the institute which indicated an average $15 \%$ drop out rate. An initial pilot study using 16 subjects was performed to help standardize the reliability of examiner in terms of clinical parameters and consistency of operator for the treatment provided.

Independent randomisation for allocation to Group 1 or Group 2 was performed using the flip of a coin. Written informed consent was obtained from each subject. Participants' social information such as education, income, previous visits, and smoking status were also recorded. Further, the SES of individuals in the Chennai urban population was subjected to 2013 Kuppuswamy tool.

\section{Clinical protocol}

Eighteen patients were treated with conventional multi-visit approach and 19 patients with single-visit RSD approach. The procedures were performed under local anesthesia: $2 \%$ lignocaine, 1:80,000 adrenaline. Buccal and palatal infiltration was given for maxillary quadrants and inferior alveolar nerve block with long buccal and lingual nerve block were given for mandibular quadrants. All the patients were given a similar dose of anesthesia. A combination of site-specific Gracey curettes (Hu-friedy, USA) and ultrasonic piezoelectric scaler (EMS, Piezon ${ }^{\circledR}$ ) were used for RSD procedure followed by polishing with prophylactic paste (Proxyt ${ }^{\circledR}$ prophy paste, Ivoclar, Vivadent). Patients were asked to take analgesics (paracetomol $500 \mathrm{mg}$ two tablets four times a day for 5 days) only if they felt necessary following wearing off the anesthesia as the patients were required to record their pain scores on visual analog scale (VAS). Only four 


\section{A total of 40 Generalised chronic periodontitis patients recruited}

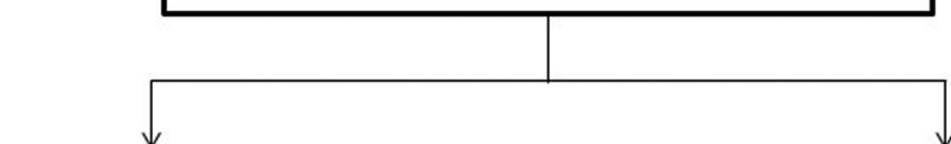

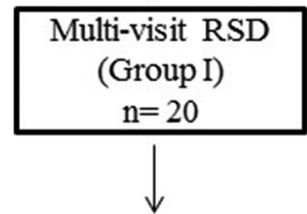
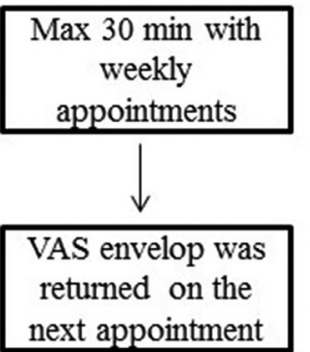

2 discontinued

Multi visit RSD

$(\mathrm{n}=18)$ completed

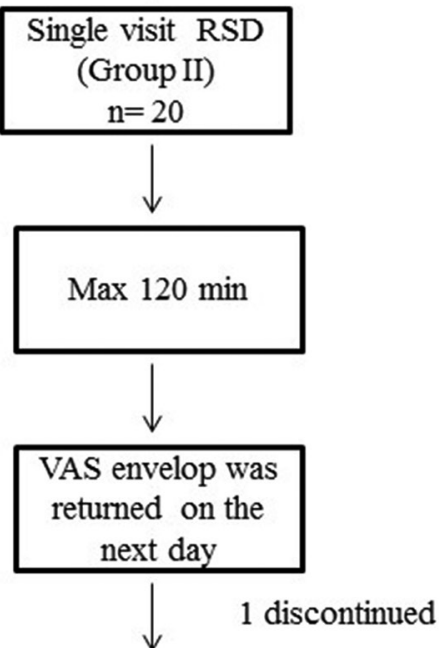

Single visit RSD

$(\mathrm{n}=19)$ completed
Figure 1: Flow chart of subject recruitment

patients out of thirty-seven reported the use of analgesics. Oral hygiene instructions were given for each patient on their first visit including Bass technique of toothbrushing and interdental brushes as appropriate and were prescribed a standard anticalculus and antigingivitis-formulated toothpaste (Colgate total). All patients were treated in a controlled clinical atmosphere by a single-experienced periodontist (VKN). The Group 1 patients were treated quadrant based in 4 visits, at an interval of 1 week and Group 2 patients were treated in a single visit.

\section{Clinical parameters}

Probing pocket depth and clinical attachment level were recorded by a single operator (AB). Assessment of anxiety and pain was performed by single operator (DA). The periodontist (VKN) was blinded to the anxiety and pain scores to avoid the incorporation of bias.

\section{Probing pocket depth}

This was assessed using UNC-15 probe (Hu-friedy, USA) from the gingival margin to the base of the pocket at 6 sites (mesiobuccal, midbuccal, distobuccal, mesiolingual, mid lingual, and distolingual).

\section{Clinical attachment level}

This was assessed using UNC-15 probe (Hu-friedy) from the cementoenamel junction to the base of the pocket at 6 sites (mesiobuccal, midbuccal, distobuccal, mesiolingual, midlingual, and distolingual).

\section{Assessment of anxiety}

All subjects were given information on the treatment to be provided and were assessed for their anxiety levels at the beginning of appointment before the start of the procedure using a self-reported questionnaire adopted by Chung et al. 2003 ${ }^{[19]}$ and Guzeldemir et al. 2008. ${ }^{[20]}$ This questionnaire consisted of 4 questions from Corah's dental anxiety scale (DAS) and 3 questions from dental fear survey (DFS) [Table 1]. In this study, we replaced the word "drill" with "instruments" in Q6 and "cleaning of your teeth" with "deep cleaning of your teeth" in Q7 to suit the treatment protocol of this study. The validity of this questionnaire was assessed before the study by administering the questionnaire to thirty patients at two different time points at 1 week interval. Group 1 patients responded to this questionnaire at each treatment visit, while Group 2 patients responded once before the treatment.

\section{Assessment of pain intensity}

The subjective perception of pain was assessed postoperatively using a $0-10 \mathrm{~cm}$ VAS. Patients were given guidance about how to score the VAS; score "0" being no pain or discomfort, and score "10" being worst pain or discomfort. Patients were discharged posttreatment with the VAS in an envelope, so subjects could complete their pain scores once the anesthetic had worn (minimum $4 \mathrm{~h}$ ) off. Subjects received verbal reminder over the phone $4 \mathrm{~h}$ after the procedure and asked to complete 
Naik, et al.: Pain and anxiety with mechanical debridement

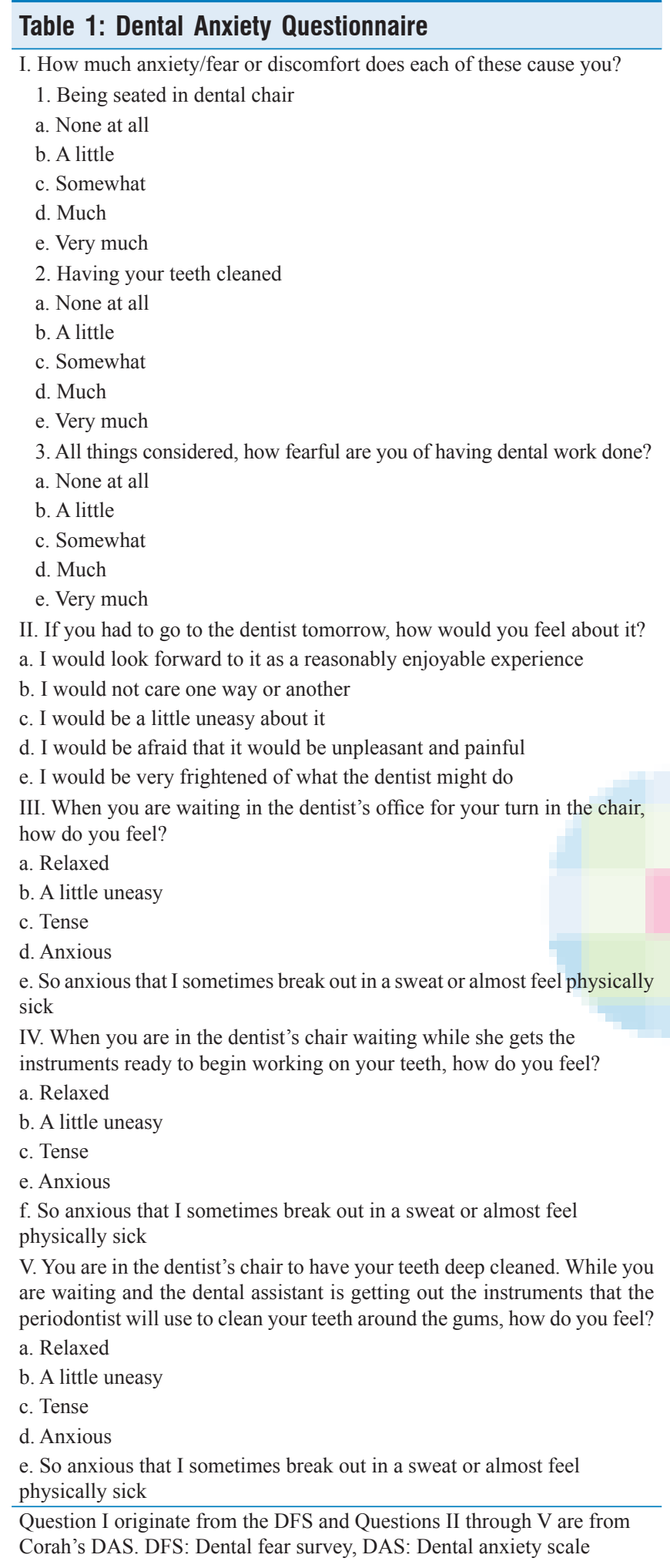

the VAS. Subjects were asked to return the completed VAS envelope at the next visit.

\section{Treatment time}

The time taken to perform the multi-visit RSD was maximum 30 min for each quadrant and for single-visit RSD maximum of $120 \mathrm{~min}$.
A flow chart of data collection and treatment provided in Group 1 and Group 2 is represented in Figure 1.

\section{Statistical analysis}

At the outset, data were presented descriptively and compared between the two groups noting the characteristics of the subjects. Data distribution pattern of the study population was assessed using Shapiro-Wilk test. Based on data distribution, parametric and nonparametric tests were used for statistical analysis. Thus, for statistical analysis, the Pearson Chi-square test and Mann-Whitney U-test were used for comparison of data and Spearman's rank correlation was used for correlation analysis between dental anxiety scores to the pain scores. SPSS, Version 20 (IBM Corp., Chicago, Illinois, USA) was used to carry out statistical analysis. $P<0.05$ was considered statistically significant for analysis.

\section{RESULTS}

\section{Characteristics of the study subjects}

A total of 37 individuals (20 females, 17 males) with chronic periodontitis were recruited in the current study and randomly divided into Group $1(n=18)$ (conventional multi-visit debridement) and Group $2(n=19)$ ( $24 \mathrm{~h} \mathrm{RSD})$. Overall, the mean age in the study population was $40.97 \pm 10.32$ years and age ranged from 25 to 64 years. Table 2 presents the descriptive characteristics of the subjects recruited. There was no significant correlation between clinical parameters and anxiety levels and pain perceptions.

There was no significant difference in the demographic and clinical variables between Group 1 and Group $2(P>0.05)$ [Table 2]. No statistical significant difference was found between the Group 1 and Group 2 with regard to mean age, education levels, previous visits to the dentist, probing pocket depth, and clinical attachment level.

Based on the scores of the Kuppuswamy scale, the population was divided into upper, upper middle, lower middle, upper lower, and lower socioeconomic class. In Group 1, 61\% of subjects and in Group 2, 58\% belonged to upper lower class. Thus, the majority of the population belonged to similar socioeconomic class, eliminating any influence in the anxiety state [Table $3 \mathrm{a}$ and $\mathrm{b}]$.

\section{Anxiety scores}

The preprocedural anxiety levels were assessed using DAS and DFS questionnaire and were validated, before the start of the study. The validity of this questionnaire was assessed by distributing to 30 patients at two different time points 1 week apart. The Cronbach's $\alpha=0.87$ indicated excellent internal consistency of the questionnaire.

Table 4 represents the comparison of anxiety scores of both the groups at visit one at baseline which showed no statistical significance.

\section{Visual analog scale scores for pain}

Pain scores were assessed using VAS of $0-10 \mathrm{~cm}$. Mean VAS scores for entire study population was $1.8 \pm 1.5 \mathrm{~cm}$ ranging 
Naik, et al.: Pain and anxiety with mechanical debridement

\begin{tabular}{|c|c|c|c|}
\hline Variables & Group 1 & Group 2 & $P$ \\
\hline Number of subjects & 18 & 19 & \\
\hline Male & 10 & 7 & 0.467 \\
\hline Female & 8 & 12 & 0.371 \\
\hline Age (mean \pm SD) & $41.72 \pm 2.69$ & $40.26 \pm 2.16$ & 0.893 \\
\hline Smokers & 2 & 4 & 0.414 \\
\hline \multicolumn{4}{|l|}{ Education } \\
\hline Secondary school & 7 & 9 & 0.229 \\
\hline Primary school & 8 & 7 & \\
\hline UG & 1 & 3 & \\
\hline PG & 2 & 0 & \\
\hline \multicolumn{4}{|c|}{ Income per month (INR) } \\
\hline 5000 & 6 & 4 & 0.869 \\
\hline 10,000 & 7 & 13 & \\
\hline$>10,000$ & 5 & 2 & \\
\hline \multicolumn{4}{|l|}{ Previous visit } \\
\hline $1^{\text {st }}$ visit & 0 & 0 & 0.223 \\
\hline $2^{\text {nd }}$ visit & 9 & 9 & \\
\hline$>2$ visits & 9 & 10 & \\
\hline \multicolumn{4}{|l|}{ Clinical parameters } \\
\hline PD & $3.71 \pm 0.22$ & $3.6 \pm 0.25$ & 0.578 \\
\hline CAL & $4.14 \pm 0.31$ & $4.13 \pm 0.27$ & 0.822 \\
\hline
\end{tabular}

SD: Standard deviation, INR: Indian rupees, PD: Probing depth, CAL: Clinical attachment loss

\begin{tabular}{|c|c|c|c|c|c|}
\hline \multirow[t]{2}{*}{ Groups } & \multicolumn{4}{|c|}{ Kuppasamy score } & \multirow[t]{2}{*}{ Total } \\
\hline & Upper & $\begin{array}{l}\text { Upper- } \\
\text { middle }\end{array}$ & $\begin{array}{l}\text { Lower } \\
\text { middle }\end{array}$ & $\begin{array}{l}\text { Upper } \\
\text { lower }\end{array}$ & \\
\hline \multicolumn{6}{|l|}{ Group 1} \\
\hline Count & 0 & 2 & 5 & 11 & 18 \\
\hline $\begin{array}{l}\text { Percentage } \\
\text { within groups }\end{array}$ & 0 & 11.1 & 27.8 & 61.1 & 100.0 \\
\hline \multicolumn{6}{|l|}{ Group 2} \\
\hline Count & 1 & 3 & 4 & 11 & 19 \\
\hline $\begin{array}{l}\text { Percentage } \\
\text { within groups }\end{array}$ & 5.3 & 15.8 & 21.1 & 57.9 & 100.0 \\
\hline \multicolumn{6}{|l|}{ Total } \\
\hline Count & 1 & 5 & 9 & 22 & 37 \\
\hline $\begin{array}{l}\text { Percentage } \\
\text { within groups }\end{array}$ & 2.7 & 13.5 & 24.3 & 59.5 & 100.0 \\
\hline
\end{tabular}

from 0 to $5 \mathrm{~cm}$. With regard to gender, the mean VAS scores for males were $1.65 \pm 1.7 \mathrm{~cm}$ ranging from 0 to $5 \mathrm{~cm}$ and for females were $1.87 \pm 1.3 \mathrm{~cm}$, ranging from 0 to $4 \mathrm{~cm}$. The comparison of VAS scores between Group 1 and 2 at baseline/visit one did not show any statistical significance with a $P=0.239$.

\section{Intragroup analysis within Group 1}

The comparison of anxiety responses within Group 1 across 4 visits is presented in Table 5 . The question 2 "having your teeth cleaned" showed a statistical significant difference in the anxiety scores with a $P=0.02$.
Table $3 \mathrm{~b}$ : Comparison of socio-economic status of group 1 and group 2 individuals based on Kuppuswamy scale

\begin{tabular}{lccc}
\hline \multicolumn{4}{c}{ Chi-square tests } \\
\hline & Value & df & $\begin{array}{c}\text { Asymptotic significant } \\
\text { (two-sided) }\end{array}$ \\
\hline Pearson Chi-square & 1.285 & 3 & 0.733 \\
Likelihood ratio & 1.672 & 3 & 0.643 \\
Linear-by-linear association & 0.453 & 1 & 0.501 \\
Number of valid cases & 37 & & \\
\hline
\end{tabular}

Table 4: Comparison of responses to anxiety questionnaire between groups at visit 1 (at baseline)

\begin{tabular}{lcc}
\hline Question number & Group 1 versus Group 2 (Pearson $\left.\boldsymbol{\chi}^{2}\right)$ & $\boldsymbol{P}$ \\
\hline 1 & 2.181 & 0.5 \\
2 & 4.62 & 0.3 \\
3 & 1.86 & 0.3 \\
4 & 1.21 & 0.8 \\
5 & 1.25 & 0.5 \\
6 & 1.51 & 0.4 \\
7 & 2.84 & 0.4 \\
\hline
\end{tabular}

The results of intragroup comparison with relation to anxiety showed a statistically significant difference between visit 3 and 4 . Further, the pain scores showed highly statistically significant difference between visit 3 and visit 1 , visit 4 and visit 1 , and between visit 2 and visit 4 as represented in Table 6 .

\section{Correlation of anxiety levels to pain score}

Finally, the anxiety scores were correlated with the pain scores in both Group 1 and 2 at visit 1 . Table 7 represents the correlation values along with the $P$ values. In Group 1, question $1,2,3$, and 7 showed a statistically significant positive correlation between anxiety and pain scores. On the contrary, in Group 2, none of the anxiety questions showed statistical significant correlation with the pain scores.

\section{Discussion}

The factors that have been shown to influence anxiety are age, gender, educational status, and SES. In this study, the subjects recruited showed similar demographics such as age, gender, educational status and SES as determined by Kuppuswamy scale and none of the subjects were completely new patients to dental treatment. Since subjects who are anxious are likely to experience more pain ${ }^{[21]}$ than those who are not anxious, at the outset, all efforts were made in this study to avoid confounding factors that may influence dental anxiety levels.

The plaque biofilm is a community of microorganisms which are spatially organized into three dimensional structure and is supported by extracellular matrix. ${ }^{[22]}$ The results of this prospective, randomized, blinded-controlled clinical study did not show differences in preprocedural dental anxiety levels and postoperative pain perceptions between single-visit RSD and conventional multi-visit RSD groups. This observation is in agreement with Santuchi et al. 2015 who conducted a 


\begin{tabular}{lcc}
\hline $\begin{array}{l}\text { Table 5: Comparison of anxiety responses within Group } \mathbf{1} \\
\text { across visits }\end{array}$ & Pearson $\chi^{2}$ & $\boldsymbol{P}$ \\
\hline Question number & 11.5 & 0.07 \\
\hline 1 & 23.2 & 0.02 \\
2 & 13.6 & 0.13 \\
3 & 11.08 & 0.5 \\
4 & 6.7 & 0.3 \\
5 & 9.9 & 0.3 \\
6 & 7.7 & 0.8 \\
7
\end{tabular}

Table 6: Intragroup comparison of anxiety and pain within Group 1

\begin{tabular}{lcccccc}
\hline Anxiety & A2-A1 & A3-A1 & A4-A1 & A3-A2 & A4-A2 & A4-A3 \\
\hline$P$ & 0.673 & 0.564 & 0.08 & 1.0 & 0.07 & $0.037^{*}$ \\
\hline Pain & P2-P1 & P3-P1 & P4-P1 & P3-P2 & P4-P2 & P4-P3 \\
\hline$P$ & 0.496 & $0.005 *$ & $0.002 *$ & 0.254 & $0.04 *$ & 0.08 \\
\hline *Statistical significance $P<0.05$ & & & &
\end{tabular}

\begin{tabular}{|c|c|c|c|c|}
\hline \multirow{2}{*}{$\begin{array}{l}\text { Question } \\
\text { number }\end{array}$} & \multicolumn{2}{|c|}{ Group 1} & \multicolumn{2}{|c|}{ Group 2} \\
\hline & $r$ & $P$ & $r$ & $P$ \\
\hline 1 & 0.73 & $0.001 *$ & 0.24 & 0.30 \\
\hline 2 & 0.60 & $0.008 *$ & 0.33 & 0.16 \\
\hline 3 & 0.70 & $0.001 *$ & 0.33 & 0.16 \\
\hline 4 & 0.46 & $0.053^{*}$ & 0.02 & 0.92 \\
\hline 5 & 0.140 & 0.580 & 0.13 & 0.58 \\
\hline 6 & 0.40 & 0.093 & 0.25 & 0.29 \\
\hline 7 & 0.55 & $0.017^{*}$ & 0.25 & 0.29 \\
\hline
\end{tabular}

6-month randomized controlled clinical trial to observe the clinical effects and patients' based outcomes with full mouth disinfection and scaling and root planing using a quadrant-based approach. ${ }^{[23]}$ Further, authors in Santuchi et al. 2015 analyzed DAS and DFS independently as well as combined questionnaire and suggested that the scores of patients' based outcomes in full mouth disinfection (FMD) groups were superior to the quadrant-based group. However, they concluded that there were no statistically significant differences observed between both groups. On the contrary, in this study, we used DAS and DFS together as a single questionnaire as previously used by Sanikop et al. 2011 in an Indian population ${ }^{[5]}$ and Guzeldemir et al. 2008. ${ }^{[20]}$ In addition, the questionnaire was evaluated for internal consistency before the start of our study.

The pain perception by each individual is very subjective and can pose problems in recording a precise degree and amount of an individual's perceived pain. ${ }^{[24]}$ There are several tools to evaluate pain perception. Self-reported tools used in dentistry to evaluate pain are often unifacial as they are easier to apply. Examples of unifacial pain assessment tools are VAS, verbal rating scale, numerical rating scale, computer graphic scale, and picture scales. ${ }^{[25]}$ The examples of multidimensional pain assessment tools such as McGill pain questionnaire have shown to be highly consistent and supposedly the best tool to evaluate pain in research. ${ }^{[25,26]}$ However, VAS is a simple measure to use, especially in research, where the purpose is to just record the pain perceived and not to evaluate all dimensions of pain characteristics. ${ }^{[26]}$ Furthermore, VAS has been shown to be reliable and has been previously used to record pain levels following periodontal treatment. ${ }^{[27-29]}$

Perceived pain will differ, dependent on treatment provided by different clinicians and in different clinical environments. To exclude this as confounding factor, a single-experienced periodontist performed RSD on all patients in a standard clinical setting.

In this study, patients with $\geq 4 \mathrm{~cm}$ VAS score reported the use of analgesics on the day of the procedure, similarly, Karadottir et al. 2002 based on their study results suggested $\geq 40 \mathrm{~mm}$ VAS score to be painful. Thus, the arbitrary thresholds of pain experience was set at $\geq 4 \mathrm{~cm}$ and overall about $10.5 \%$ of the recruited population showed $\geq 4 \mathrm{~cm}$ of arbitrary pain threshold and this is slightly lower percentage in comparison to Karadottir et al. 2002, ${ }^{[7]}$ who reported $15 \%$ of patients experiencing pain. This most likely can be attributed to different study design, study population, use of hand instruments, and number of operators. Canakçi and Canakçi 2007 suggested that periodontal therapies were perceived as painful by GCP patients. Further postoperative pain was higher with surgical procedures which involved exposure of bone and increased time duration than with RSD. ${ }^{[27]}$ Overall, our results are in agreement with Canakçi and Canakçi 2007 who also used a single-experienced operator to carry out all procedures. Similarly, Mei et al. 2016 suggested mild pain following periodontal and implant surgeries. Further, the duration, complexity of surgery, and additional anesthetic volume used increases local tissue expansion and the production of pro-inflammatory mediators, which stimulates the nociceptors influencing pain perceived ${ }^{\left[{ }^{[30]}\right.}$ However, we did not administer additional local anesthetic to any of our study subjects and standardized the volume that was used.

In the current study, in Group 1, patients came four times to complete the RSD and there was significant reduction in the anxiety levels between visit 4 and visit 3 . Whereas Heaton et al. 2007 did not report any difference in anxiety levels with the past experience of a particular treatment or with the same clinician. However, they concluded that the results of earlier research in this regard had been conflicting. ${ }^{[31]}$

We observed a positive correlation of Q1-Q4 anxiety questions to the pain scores at the visit 1 in Group 1: Q1 being seated in the dental chair, Q2 having your teeth cleaned, Q3 all things considered, how fearful are you of having dental work done? And Q4 if you had to go to the dentist tomorrow, how would you feel about it? Showed a positive correlation to the VAS scores which were statistically significant. Whereas Karadottir et al. $2002^{[7]}$ showed positive correlation of anxiety 
responses for Q4-Q7 (Corah's DAS) to the pain scores during instrumentation which were statistically significant. Both our study and Karadottir et al. $2002^{[7]}$ showed similar correlation for Q4 which suggests patients experienced more anxiety and pain when they had to come back for the treatment.

Interestingly, in Group 2, although the anxiety questions positively correlated with the pain scores, they were not statistically significant. This suggests that Q4, if you had to go to dentist tomorrow, how would you feel about it? Clearly did not apply for Group 2 population, as they were assured that the RSD will be completed within $24 \mathrm{~h}$.

Although dental anxiety levels progressively reduced in Group 1, dental anxiety was still a significant predictor for pain experience as per the correlation analysis. Dental anxiety is suggested to be cognitively acquired negative-conditioned response to undesirable stimuli in dental environment influenced by family relatives, peer groups, and information media. ${ }^{[32]}$ Thus, Group 1 RSD patients were possibly conditioned or cognitively learned the feeling of anxiety at each visit of their procedure, but this was not observed in Group 2 single-visit RSD patients as they possibly did not have a chance to cognitively condition their anxious experience.

Furthermore, the pain scores did not differ between the two groups. However, as with the anxiety scores, the pain scores also significantly reduced between visit 3 and visit 1 ; between visit 4 and visit 1 and visit 4 and visit 2 in Group 1 . This observation is similar to that of Van Steenberghe et al. 2004, who attributed these results to the familiarity of the clinical environment, operator, and the procedure itself by the patients. ${ }^{[3]}$

Further, our findings differed from Kocher et al. 2005 who suggested the pain scores be zero. This can be implied to a different piezo-driven ultrasonic device used (Vector System ${ }^{\circledR}$ ) in their study. ${ }^{[33]}$ Thus, in this study, the use of piezoelectric scaler may have given different results compared to Kocher et al. 2005 ${ }^{[33]}$ and Karadottir et al. 2002.[7]

In the current study, the pain experienced during subsequent visits in Group 1 significantly reduced from visit 1 . This is in agreement with Van Steenberg et al. 2004 who suggested that a series of factors could be responsible for such an observation. ${ }^{[3]}$ The main reason being the familiarity of the clinical setting, the procedure itself, and/or the operator.

In our study, we used standardized and controlled clinical environment for all the subjects as environmental factors can influence pain perception. We scheduled all our patients during the same time of the day (Forenoon) and thus we have possibly reduced the impact of any external factors influencing pain perception. In addition, we recorded pain scores $4 \mathrm{~h}$ after the procedure so as to reduce any different memory effects on pain perception with longer time lapse.

In this study, we did not measure physiological aspect of anxiety such as blood pressure and heart rate which would have been an interesting additional measure to support the self-reported anxiety data.

\section{Conclusion}

This study aimed to investigate and compare preprocedural anxiety levels and postprocedural pain perception in single multi-visit and conventional quadrant-wise multi-visit RSD procedures. However, the results suggested both procedures did not show any significant differences in dental anxiety levels or pain perception. Based on the results of this study, it can be concluded that in Group 1 patients, anxiety can be a significant predictor for pain. Within the limitations of this study, single-visit RSD appears to be a favorable option in highly anxious generalized chronic periodontitis subjects requiring RSD. Further, explaining the procedure seems to ease the patient's anxiety levels and pain experienced. Hence, all efforts should be made to ease their anxiety during RSD procedures.

\section{Acknowledgments}

We would like to acknowledge all patients who participated in this study and the management of SRM Dental College, Ramapuram, Chennai, India.

\section{Financial support and sponsorship}

Nil.

Conflicts of interest

There are no conflicts of interest.

\section{ReFERENCES}

1. Klingberg G, Broberg AG. Dental fear/anxiety and dental behaviour management problems in children and adolescents: A review of prevalence and concomitant psychological factors. Int J Paediatr Dent 2007;17:391-406.

2. Sohn W, Ismail AI. Regular dental visits and dental anxiety in an adult dentate population. J Am Dent Assoc 2005;136:58-66.

3. van Steenberghe D, Garmyn P, Geers L, Hendrickx E, Maréchal M, Huizar K, et al. Patients' experience of pain and discomfort during instrumentation in the diagnosis and non-surgical treatment of periodontitis. J Periodontol 2004;75:1465-70.

4. Hassan MA, Bogle G, Quishenbery M, Stephens D, Riggs M, Egelberg J. Pain experienced by patients during periodontal recall examination using thinner versus thicker probes. J Periodontol 2005;76:980-4.

5. Sanikop S, Agrawal P, Patil S. Relationship between dental anxiety and pain perception during scaling. J Oral Sci 2011;53:341-8.

6. Al-Hamdan K. Pain perception following different periodontal procedures. Pak Oral Dent J 2009;29:63-8.

7. Karadottir H, Lenoir L, Barbierato B, Bogle M, Riggs M, Sigurdsson T, et al. Pain experienced by patients during periodontal maintenance treatment. J Periodontol 2002;73:536-42.

8. Saini R. A prospective experimental comparative study on the clinical effects of calculus dissolution based oral rinse in gingivitis patients. Int J Exp Dent Sci 2015;4:33-9.

9. Mombelli A, Tonetti M, Lehmann B, Lang NP. Topographic distribution of black-pigmenting anaerobes before and after periodontal treatment by local delivery of tetracycline. J Clin Periodontol 1996;23:906-13.

10. van Winkelhoff AJ, van der Velden U, de Graaff J. Microbial succession in recolonizing deep periodontal pockets after a single course of supra- and subgingival debridement. J Clin Periodontol 1988;15:116-22.

11. Quirynen M, Bollen CM, Vandekerckhove BN, Dekeyser C, Papaioannou W, Eyssen H. Full-vs. partial-mouth disinfection in 
the treatment of periodontal infections: Short-term clinical and microbiological observations. J Dent Res 1995;74:1459-67.

12. Eberhard J, Jepsen S, Jervøe Storm PM, Needleman I, Worthington HV. Full mouth treatment modalities (within 24 hours) forchronic periodontitis in adults. Cochrane Database Syst Rev 2015:CD004622.

13. Eberhard J, Jervøe-Storm PM, Needleman I, Worthington H, Jepsen S. Full-mouth treatment concepts for chronic periodontitis: A systematic review. J Clin Periodontol 2008;35:591-604.

14. Tomasi C, Wennström JL. Full-mouth treatment vs. the conventional staged approach for periodontal infection control. Periodontol 2000 2009;51:45-62.

15. Ng SK, Leung WK. Oral health-related quality of life and periodontal status. Community Dent Oral Epidemiol 2006;34:114-22.

16. Armitage GC. Development of a classification system for periodontal diseases and conditions. Ann Periodontol 1999;4:1-6.

17. Yildirim TT. Evaluating the relationship of dental fear with dental health status and awareness. J Clin Diagn Res 2016;10:ZC105-9.

18. Sharma R. Kuppuswamy's socioeconomic status scale - Revision for 2011 and formula for real-time updating. Indian J Pediatr 2012;79:961-2.

19. Chung DT, Bogle G, Bernardini M, Stephens D, Riggs ML, Egelberg JH. Pain experienced by patients during periodontal maintenance. J Periodontol 2003;74:1293-301.

20. Guzeldemir E, Toygar HU, Cilasun U. Pain perception and anxiety during scaling in periodontally healthy subjects. J Periodontol 2008;79:2247-55

21. van Wijk AJ, Makkes PC. Highly anxious dental patients report more pain during dental injections. Br Dent J 2008;205:E7.

22. Saini R, Saini S, Sharma S. Biofilm: A dental microbial infection. J Nat Sci Biol Med 2011;2:71-5.

23. Santuchi CC, Cortelli SC, Cortelli JR, Cota LO, Alencar CO, Costa FO.
Pre- and post-treatment experiences of fear, anxiety, and pain among chronic periodontitis patients treated by scaling and root planing per quadrant versus one-stage full-mouth disinfection: A 6-month randomized controlled clinical trial. J Clin Periodontol 2015;42:1024-31.

24. Odai ED, Ehizele AO, Enabulele JE. Assessment of pain among a group of Nigerian dental patients. BMC Res Notes 2015;8:251.

25. Poppe K, Blue C. Subjective pain perception during calculus detection with use of a periodontal endoscope. J Dent Hyg 2014;88:114-23.

26. Ngamkham S, Vincent C, Finnegan L, Holden JE, Wang ZJ, Wilkie DJ. The McGill Pain Questionnaire as a multidimensional measure in people with cancer: An integrative review. Pain Manag Nurs 2012;13:27-51.

27. Canakçi CF, Canakçi V. Pain experienced by patients undergoing different periodontal therapies. J Am Dent Assoc 2007;138:1563-73.

28. Grant DA, Lie T, Clark SM, Adams DF. Pain and discomfort levels in patients during root surface debridement with sonic metal or plastic inserts. J Periodontol 1993;64:645-50.

29. Matthews DC, McCulloch CA. Evaluating patient perceptions as short-term outcomes of periodontal treatment: A comparison of surgical and non-surgical therapy. J Periodontol 1993;64:990-7.

30. Mei CC, Lee FY, Yeh HC. Assessment of pain perception following periodontal and implant surgeries. J Clin Periodontol 2016;43:1151-9.

31. Heaton LJ, Garcia LJ, Gledhill LW, Beesley KA, Coldwell SE. Development and validation of the Spanish Interval Scale of Anxiety Response (ISAR). Anesth Prog 2007;54:100-8.

32. Lin CS, Lee SY. Dental anxiety and expectation of pain: Cognitive modulation of the pain experience of dental patients. J Dent Sci 2007;2:129-35.

33. Kocher T, Fanghänel J, Schwahn C, Rühling A. A new ultrasonic device in maintenance therapy: Perception of pain and clinical efficacy. J Clin Periodontol 2005;32:425-9. 